\title{
In Situ Synthesis of Polymer/Clay Nanocomposites by Type II Photoinitiated Free Radical Polymerization
}

\author{
CAGATAY ALTINKOK, ${ }^{1}$ TAMER UYAR, ${ }^{2}$ MEHMET ATILLA TASDELEN, ${ }^{1,3}$ YUSUF YAGCI $^{1}$ \\ ${ }^{1}$ Department of Chemistry, Istanbul Technical University, Maslak, Istanbul 34469, Turkey \\ ${ }^{2}$ UNAM-Institute of Materials Science and Nanotechnology, Bilkent University, 06800 Ankara, Turkey \\ ${ }^{3}$ Department of Polymer Engineering, Faculty of Engineering, Yalova University, TR-77100 Yalova, Turkey
}

Received 25 January 2011; accepted 21 May 2011

DOI: $10.1002 /$ pola. 24788

Published online 14 June 2011 in Wiley Online Library (wileyonlinelibrary.com).

KEYWORDS: montmorillonite; polymer/clay nanocomposite; poly(methyl methacrylate); radical polymerization; Type II photopolymerization; visible light initiation

INTRODUCTION Polymer/clay nanocomposites, in which nanosized silicate plates of clay are uniformly dispersed in the polymer matrix, provide enhanced mechanical and thermal properties compared to conventional composites. ${ }^{1-3}$ Not all polymer and clay combinations will form nanocomposites: the compatibility and interfacial properties between polymer matrix and clay layers significantly influence the essential characteristics of materials. Generally, the clays have poor compatibility with the polymer matrix, except for water soluble polymers. Therefore, the clay must be organically modified using organic surfactants to improve compatibility. The nanocomposites can be formed by the following four principal methods, namely, solution exfoliation, melt intercalation, in situ polymerization, and template synthesis. ${ }^{1-3}$ In situ polymerization technique is the mostly used way to prepare the nanocomposites because of the types of nanofillers and polymer precursors can be varied in a wide range to achieve desired properties. In this case, the monomer together with the initiator and/or catalyst is intercalated within the silicate layers, and the polymerization is initiated by external stimulation such as thermal, photochemical, or chemical activations. Various in situ polymerization techniques, including conventional free radical polymerization, ${ }^{4-8}$ controlled radical polymerization, ${ }^{9-15}$ ring-opening polymerization, ${ }^{16-22}$ ring-opening metathesis polymerization, ${ }^{23-25}$ cationic polymerization, ${ }^{14,26-29}$ and anionic polymerization, ${ }^{30,31}$ have been reported and summarized in our recent review article. ${ }^{32}$ Among them, the conventional free radical polymerization is the most practical and simple route in such applications because of its applicability to a wide range of monomers. Photoinitiated free radical polymerization offers several advantages over thermally initiated free radical polymerization, including low-temperature conditions, solvent-free formulation, and a rapid polymerization rate. ${ }^{33}$ The photoiniti- ated free radical polymerization can be initiated by both cleavage (Type I) and H-abstraction type (Type II) photoinitiators. ${ }^{34}$ Type II photoinitiators undergo a bimolecular reaction where the excited state of the photoinitiator interacts with a hydrogen donor to generate free radicals. ${ }^{35-37}$ Because of their better optical absorption properties in the near-UV spectral region, these type photoinitiators are preferred in applications where the long wavelength absorption is required. ${ }^{38-43}$

Recent efforts in our group have focused on the use of in situ photoinitiated polymerization for the preparation of polymer/clay nanocomposites. ${ }^{6-8,27}$ Attachment of either photoactive groups photoinitiator ${ }^{6}$ or nonphotoactive groups such as monomer ${ }^{8}$ or chain transfer agent ${ }^{7,27}$ into clay layers and subsequent photopolymerization of immersed monomers facilitate propagation and exfoliation processes concomitantly, leading to the formation of homogeneous claypolymer nanocomposites.

As part of our continuing interest in developing strategies for the preparation of polymer/clay nanocomposites, we now report on a new synthetic route by using tertiary amine functionalized clay as a hydrogen donor in Type II photoinitiated free radical polymerization. The method consists of the intercalation of 4-(dimethylamino)benzoate (DMAB) group into silicate layers by esterification reaction and followed by in situ photopolymerization of methyl methacrylate (MMA), which leads to polymer/clay nanocomposites. The effects of the type of photoinitiator as well as irradiation wavelength and clay content on the photopolymerization are also investigated.

\section{RESULTS AND DISCUSSION}

Type II photoinitiated polymerization can be initiated by combination of a photosensitizer and a hydrogen donor via hydrogen abstraction mechanism. It was recently 


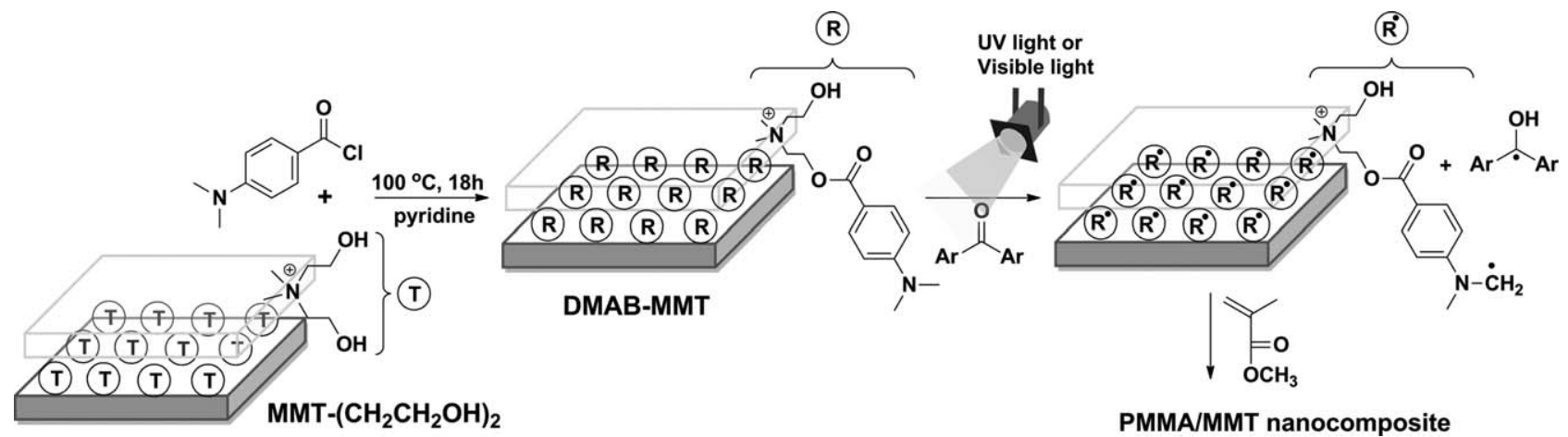

SCHEIME 1 Incorporation of 4-(dimethylamino)benzoate group into MMT- $\left(\mathrm{CH}_{2} \mathrm{CH}_{2} \mathrm{OH}\right)_{2}$ and preparation PMMA/MMT nanocomposites by in situ Type II photoinitiated free radical polymerization.

demonstrated that this mechanism was used to graft polymer onto self-assembled monolayers (SAM). ${ }^{44}$ On irradiation, the excited triple state benzophenone (BP) formed and abstracted hydrogen from the amine anchored on the SAM surface. The resulting radical on the surface could initiate the polymerization of MMA, whereas the ketyl radical was not, and usually condenses to form benzopinacol derivatives. This way, the formation of noncovalently bonded polymer chains from SAM surface could be avoided. In this study, we took advantage of similar hydrogen abstraction reaction of the triplet photosensitizers from tertiary amines for the preparation of polymer/clay nanocomposites. For the incorporation of tertiary amine units into clay layers, 4-(dimethylamino)benzoyl chloride was firstly used to react with commercial montmorillonite clay containing two hydroxyl groups Cloisite 30B [MMT- $\left(\mathrm{CH}_{2} \mathrm{CH}_{2} \mathrm{OH}\right)_{2}$ ] in pyridine (Scheme 1). The FT-IR spectrum of resulting 4-(dimethylamino)benzoate functional montmorillonite (DMAB-MMT) clay showed that a characteristic carbonyl peak at $1640 \mathrm{~cm}^{-1}(\mathrm{C}=0$, stretching) and aromatic peaks at $3050(\mathrm{C}-\mathrm{H}$, stretching), $1540(\mathrm{C}-\mathrm{C}$ stretching), 750, and $680 \mathrm{~cm}^{-1}(\mathrm{C}-\mathrm{H}$, "oop") corresponding to benzoyl moiety, whereas a broad peak at around 3400 $\mathrm{cm}^{-1}$ indicates that small amount of nonfunctionalized hydroxy groups on the surface of the layers was still remained. However, this would not affect the ultimate target as the existing tertiary amine units would provide sufficient hydrogen-donating sites for Type II photopolymerization.

The interlayer spacing of organomodified clays were determined by the angular position $2 \theta$ in X-ray Diffraction (XRD) pattern using the Bragg formula, $\lambda=2 d \sin \theta$ [the wavelength $(\lambda)$ of $X$ ray was $1.5 \AA$ ]. After the esterification reaction, the diffraction peak of MMT- $\left(\mathrm{CH}_{2} \mathrm{CH}_{2} \mathrm{OH}\right)_{2}$, 4.94 with a basal spacing of $1.86 \mathrm{~nm}$, shifted to $4.86^{\circ}$ with a basal spacing of $1.89 \mathrm{~nm}$ in DMAB-MMT (Fig. 1). The expanded basal spacing suggests that the DMAB group was successfully incorporated into the silicate galleries of MMT, which was a good agreement with the FT-IR results.

Poly(methyl methacrylate)/montmorillonite (PMMA/MMT) nanocomposites were prepared by in situ Type II photoinitiated polymerization of DMAB-MMT and MMA monomers under either UV or visible light irradiation (Scheme 1). Both visible and UV light photosensitizers, namely, camphorqui- none (CQ) and benzophenone (BP), respectively, were able to initiate the polymerization of MMA through the hydrogen abstraction from the DMAB-MMT clay. Therefore, the radicals on the silicate layers not only initiated the polymerization but also facilitated the propagation and exfoliation processes, concurrently. Table 1 summarized the experimental conditions and properties of PMMA/MMT nanocomposites prepared by visible or UV light-initiated polymerization.

It was noted that, the conversion of MMA in both system increased in the order of organomodified clay contents which was directly related to the hydrogen donating sites. Obviously, this would lead to the generation of higher number of free radicals resulting in slightly higher conversion.

After the successful polymerization of MMA, the diffraction peak of DMAB-MMT disappeared in the XRD pattern of all nanocomposites (Fig. 1). The absence of diffraction peaks were a typical proof of completely exfoliated structures in the nanocomposites. However, it was well known that XRD information alone was not sufficient to characterize nanocomposite morphology particularly when the amount of clay was low. For a complete characterization of nanocomposite

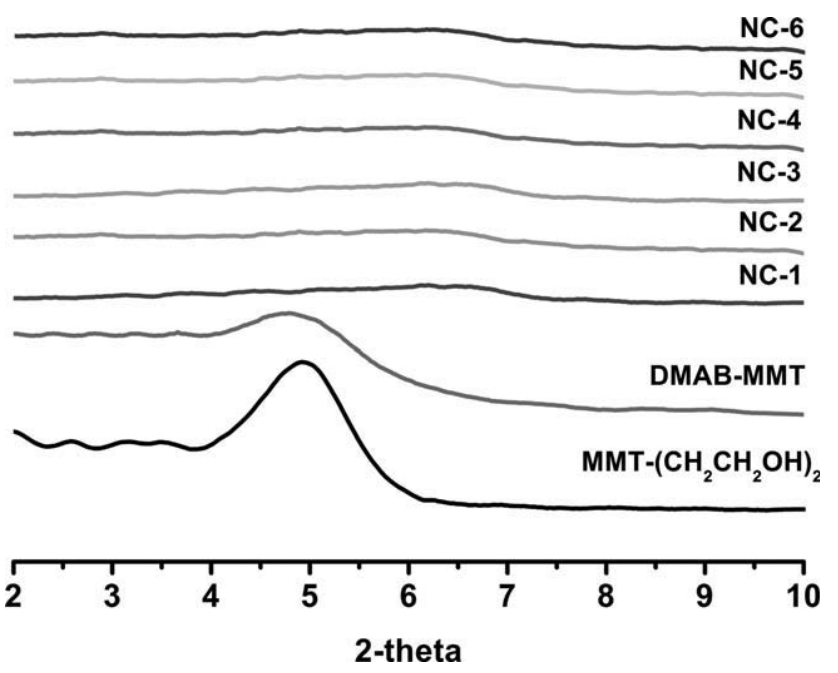

FIGURE 1 X-ray diffractions of MMT- $\left(\mathrm{CH}_{2} \mathrm{CH}_{2} \mathrm{OH}\right)_{2}$, DMABMMT, and all nanocomposites. 
TABLE 1 Visible or UV Light-Initiated Polymerization ${ }^{a}$ of Methyl Methacrylate in the Presence of DMAB-MMT and Thermal Properties of Resulting Nanocomposites

\begin{tabular}{|c|c|c|c|c|c|c|c|}
\hline \multirow[b]{2}{*}{ Samples } & \multirow[b]{2}{*}{ DMAB-MMT (wt \%) } & \multirow[b]{2}{*}{ Photosensitizer $^{\mathrm{b}}$} & \multirow[b]{2}{*}{ Conv. $^{c}(\%)$} & \multirow[b]{2}{*}{$T_{\mathrm{g}}^{\mathrm{d}}\left({ }^{\circ} \mathrm{C}\right)$} & \multicolumn{2}{|c|}{$\begin{array}{l}\text { Weight Loss } \\
\text { Temperature }^{\mathrm{e}}\end{array}$} & \multirow[b]{2}{*}{ Char Yield $^{\mathrm{e}}(\%)$} \\
\hline & & & & & $T_{0.1}$ & $T_{0.5}$ & \\
\hline PMMA & - & $\mathrm{CO}$ & 42 & 131.1 & 264.1 & 358.2 & - \\
\hline NC-1 & 1 & $\mathrm{CO}$ & 35 & 131.4 & 276.2 & 362.6 & 3.1 \\
\hline NC-2 & 3 & $\mathrm{CQ}$ & 46 & 132.1 & 291.9 & 365.2 & 9.6 \\
\hline NC-3 & 5 & $\mathrm{CQ}$ & 53 & 133.2 & 295.5 & 368.9 & 12.6 \\
\hline NC-4 & 1 & $\mathrm{BP}$ & 33 & 131.8 & 282.1 & 361.4 & 5.3 \\
\hline NC-5 & 3 & $\mathrm{BP}$ & 39 & 132.6 & 283.4 & 364.8 & 10.5 \\
\hline NC-6 & 5 & $\mathrm{BP}$ & 43 & 133.8 & 284.6 & 365.2 & 15.8 \\
\hline
\end{tabular}

${ }^{b}$ With the same weight percentage of clay.

morphology, the most frequently used technique was the combination of XRD and transmission electron microscopic (TEM) analyses. To confirm the XRD results, the morphologies of the nanocomposites were further investigated by TEM analysis. Several images for NC-1 were collected at high and low magnification in Figure 2. The low magnification image showed the general dispersion of clay layers in the PMMA matrix, whereas a higher magnification images clearly identified single and multilayer platelets of DMAB-MMT. The dark lines represented the intersection of silicate layers about $1.0 \mathrm{~nm}$ thick and from 50 to $100 \mathrm{~nm}$ in lateral dimension, which were oriented perpendicularly to the slicing plane whereas the gray background corresponds to PMMA phase. The platelet layers for the $\mathrm{NC}-1$ were a mixture of fully exfoliated (e) and intercalated (i) structures (Fig. 2).

The same morphology and distribution were also observed for the NC-2 and NC-3 samples (Fig. 3). Based on the XRD results and TEM micrographs, it can be concluded that partially exfoliated/intercalated structures were achieved in all PMMA/MMT nanocomposite samples prepared by visible light irradiation. The intercalated structures might be due to termination by recombination of growing radicals attached on facing clay layers, thus preventing further increase of the interlayer spacing.

The glass transition temperatures $\left(T_{\mathrm{g}}\right)$ s of pure PMMA and PMMA/MMT nanocomposites measured by differential scanning calorimetry (DSC) were shown in Table 1. The PMMA/ MMT nanocomposites generally had higher $T_{\mathrm{g}}$ compared to that of pristine PMMA, $131.1{ }^{\circ} \mathrm{C}$, which showed that the chain mobility of PMMA was reduced by interaction with silicate layers. Overall, the amount of clay had a negligible or very limited influence on the glass transition region of PMMA. Typical thermal gravimetric analysis (TGA) curves for virgin PMMA and PMMA/MMT nanocomposites prepared by either visible or UV light irradiation were shown in Figure 4 and all the results were collected in Table 1 . There were three main degradation stages of PMMA, including head-to-head linkages between 160 and $240{ }^{\circ} \mathrm{C}$, end chain saturation around $290{ }^{\circ} \mathrm{C}$, and random scission of the polymer chains between 300 and $400{ }^{\circ} \mathrm{C}^{8,45} \mathrm{In}$ Figure 4, the pure PMMA showed these three reaction stages, whereas the nanocomposites displayed mainly the third stage
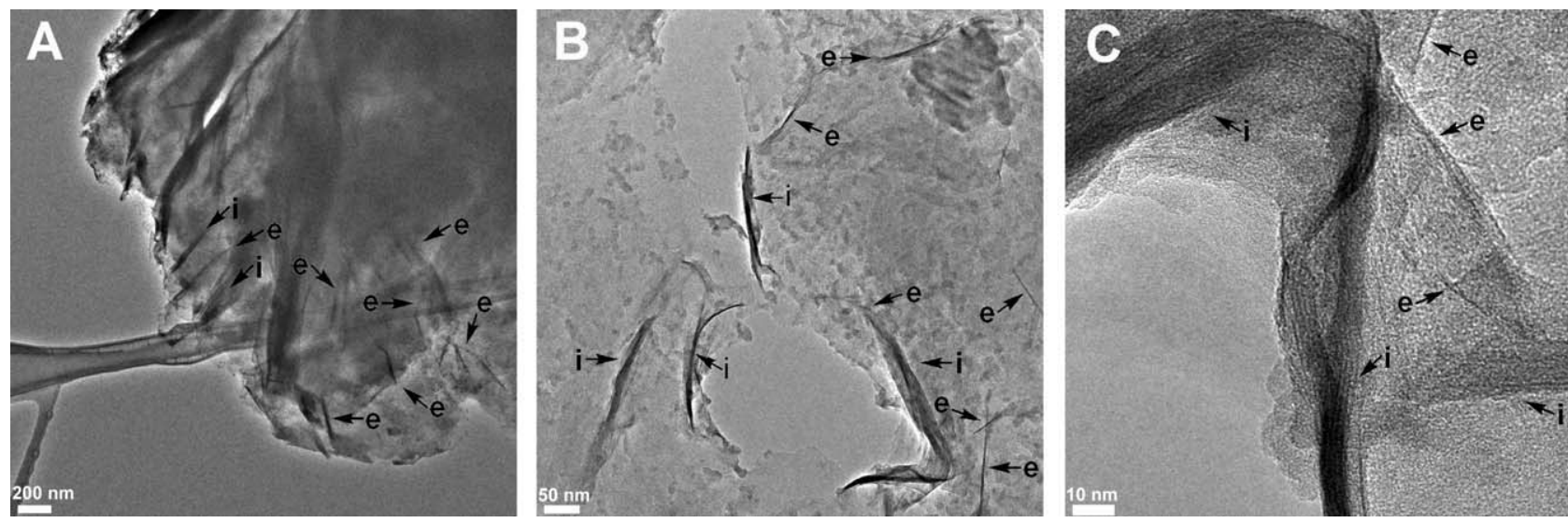

FIGURE 2 TEM micrographs showing exfoliated/intercalated silicate layers in NC-1 sample at different magnifications (A, $200 \mathrm{~nm}$; $\mathrm{B}, 50 \mathrm{~nm}$; and C, $10 \mathrm{~nm}$ ). 

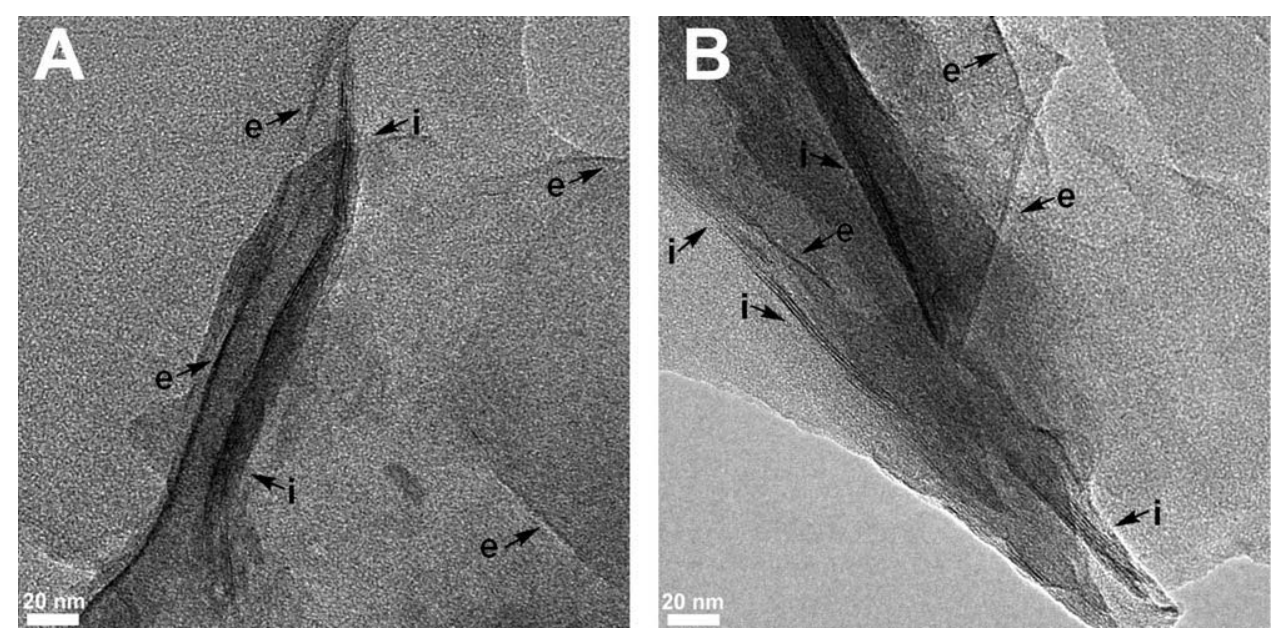

FIGURE 3 TEM micrographs showing exfoliated/intercalated silicate layers in NC-2 and NC-3 samples at $20 \mathrm{~nm}$ magnifications.

indicating random scission decomposition. Only the NC-1 samples exhibited two degradation stages, which may be due to insufficient clay dispersion by visible light irradiation. On the other hand, the $T_{0.1}$ and $T_{0.5}$ of all nanocomposites increased with increasing silicate content in both cases. This increase in the visible light-initiated nanocomposites (NC-1, NC-2, and NC3) was much higher than those initiated by UV light (NC-4, NC-5, and NC-6). In addition, PMMA/MMT nanocomposites obviously had greater char yield than neat PMMA, which also increased on increasing the clay content, as expected.

\section{EXPERIMENTAL}

\section{Materials}

4-(Dimethylamino) benzoyl chloride (DMAB, 97\%, Alfa Aesar, CQ (98\%, Fluka) and pyridine (Labscan) were used as received. MMA (99\%, Aldrich) was passed through basic alumina column to remove the inhibitor. BP (99\%, Acros) was used after being recrystallized from ethanol. Organomodified clay, Cloisite 30B (MMT- $\left.\left(\mathrm{CH}_{2} \mathrm{CH}_{2} \mathrm{OH}\right)_{2}\right)$ was purchased from Southern Clay Products (Gonzales, TX). The clay was a MMT modified by methyl bis(2-hydroxyethyl) (tallow alkyl) ammo- nium ions. The organic content of the organomodified MMT, determined by TGA, was 21 wt \%. Before use, the clay was dried under vacuum at $110{ }^{\circ} \mathrm{C}$ for $1 \mathrm{~h}$.

\section{Modification of MMT- $\left(\mathrm{CH}_{2} \mathrm{CH}_{2} \mathrm{OH}\right)_{2}$ with 4-(Dimethylamino)benzoyl Chloride}

Methyl bis(2-hydroxyethyl) (tallow alkyl) ammonium organomodified clay (MMT- $\left(\mathrm{CH}_{2} \mathrm{CH}_{2} \mathrm{OH}\right)_{2}, 0.50 \mathrm{~g}, 0.61 \mathrm{mmol}, \mathrm{OH}$ content) and 4-(dimethylamino)benzoyl chloride (0.12 g, $10.61 \mathrm{mmol})$ were added in pyridine $(50 \mathrm{~mL})$. This mixture was flushed with nitrogen for $30 \mathrm{~min}$, and it was heated to $100{ }^{\circ} \mathrm{C}$ for $18 \mathrm{~h}$ with continuous stirring. After cooling to room temperature and removing the solvent by rotary evaporation, tetrahydrofuran $(200 \mathrm{~mL})$ was added to the crude reaction mixture and washed five times with THF. The clay was then filtered off on a cold silica filter, washed with water, and finally dried in vacuum.

Yield, 71\% and organic content, 22.5\%; FT-IR (attenuated total reflectance (ATR), $\left.\mathrm{cm}^{-1}\right): 3400(-\mathrm{OH}), 3050(-\mathrm{CH}, \mathrm{Ar})$ $2965\left(-\mathrm{CH}_{3}\right), 2870\left(-\mathrm{CH}_{2}\right), 1640(-\mathrm{C}=0), 1540(-\mathrm{C}-\mathrm{C})$, 750 and $680 \mathrm{~cm}^{-1}(-\mathrm{C}-\mathrm{H}, \mathrm{Ar})$.
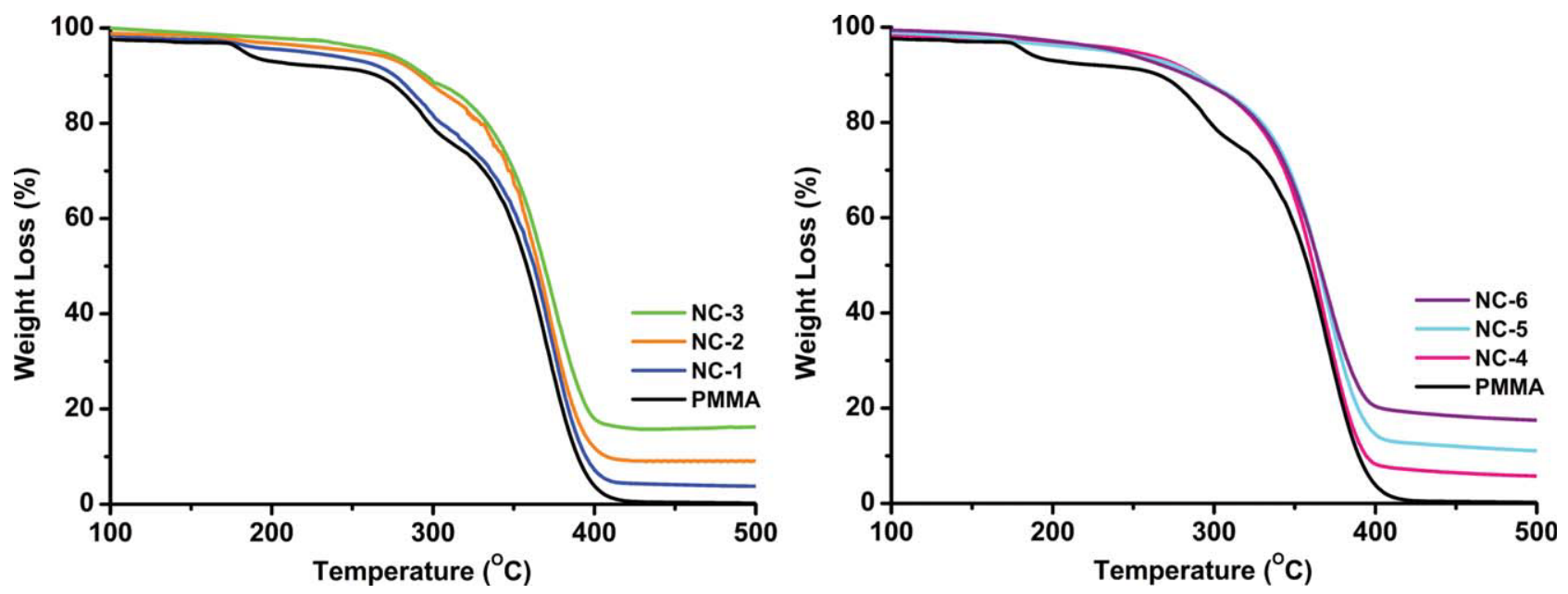

FIGURE 4. TGA thermograms of MMT- $\left(\mathrm{CH}_{2} \mathrm{CH}_{2} \mathrm{OH}\right)_{2}$, DMAB-MMT, and NC1-NC6 nanocomposites. 


\section{Preparation of the PMMA/MMT Nanocomposites}

The DMAB-MMT clay $(1,3$, and $5 \%$ of the monomer by weight) and a photoinitiator (with the same weight percentage of clay) were mixed with MMA monomer (1 mL) monomer in Pyrex tubes via a magnetic stirrer at room temperature for $3 \mathrm{~h}$ and degassed with nitrogen before irradiation. Depending on the type of photoinitiator, two photoreactors were used to conduct the polymerization in which the sample was surrounded by a circle of 16 lamps (Philips 8W/06) emitting light nominally at $350 \mathrm{~nm}$ (Rayonet merry-go-round photoreactor) or a circle of six lamps (Philips TL-D $18 \mathrm{~W}$ ) emitting light nominally at 400-500 nm (Ker-Vis blue photoreactor). At the end of $3 \mathrm{~h}$, the polymers precipitated into methanol were filtered, dried, and weighed.

\section{Characterization}

Fourier transform infrared (FT-IR) spectra were recorded on a PerkinElmer FT-IR Spectrum One B spectrometer. The thermal transition of the polymers was measured under nitrogen flow using a differential scanning calorimeter (PerkinElmer Diamond DSC) at a heating rate of $10{ }^{\circ} \mathrm{C} \mathrm{min}^{-1}$ from 50 to $200{ }^{\circ} \mathrm{C}$. Thermal gravimetric analysis was performed on PerkinElmer Diamond TA/TGA with a heating rate of $10{ }^{\circ} \mathrm{C}$ min under nitrogen flow. Wide angle X-ray diffraction measurements were conducted on a Rigaku D/Max-Ultimate diffractometer with $\mathrm{CuK}_{\alpha}$ radiation $\left(\lambda=1.54{ }^{\circ} \mathrm{A}\right)$, operating at $40 \mathrm{kV}$ and $40 \mathrm{~mA}$. TEM imaging was carried out by FEI Tecnai ${ }^{\mathrm{TM}} \mathrm{G}^{2}$ F30 instrument operating at an acceleration voltage of $300 \mathrm{kV}$.

\section{CONCLUSIONS}

Dimethylaminobenzoate-functionalized clay has been prepared by esterification reaction between 4-(dimethylamino)benzoyl chloride and commercial Cloisite 30B clay containing two hydroxyl groups and used to produce PMMA/MMT nanocomposites by in situ Type II photoinitiated free radical polymerization. The polymerization can be initiated by combination of BP or CQ and dimethylaminobenzoate-functionalized clay under either visible or UV light irradiation, respectively. The polymerization through into the silicate layers lead to PMMA/MMT nanocomposites which were formed by individually dispersing inorganic silica nanolayers in the polymer matrix. The random dispersion of silicate layers in the polymer matrix was confirmed by XRD and TEM measurements. Thermal stability of all nanocomposites prepared under both irradiation conditions is improved relative to that of pristine PMMA. The char yields increased on by increasing the clay content. This work and our previous reports ${ }^{6}$ clearly demonstrate that in situ photoinitiated free radical polymerization is an elegant way to prepare polymer/clay nanocomposites at room temperature through either incorporation a chromophoric or a monomeric group as photoinitiator or polymerizable monomer, respectively, into clay layers.

\section{REFERENCES AND NOTES}

1 Okamoto, M. Mater Sci Technol 2006, 22, 756-779.

2 Ray, S. S.; Okamoto, M. Prog Polym Sci 2003, 28, 1539-1641.
3 Alexandre, M.; Dubois, P. Mater Sci Eng R 2000, 28, 1-63.

4 Okamoto, M.; Morita, S.; Taguchi, H.; Kim, Y. H.; Kotaka, T.; Tateyama, H. Polymer 2000, 41, 3887-3890.

5 Fu, X.; Qutubuddin, S. Polymer 2001, 42, 807-813.

6 Nese, A.; Sen, S.; Tasdelen, M. A.; Nugay, N.; Yagci, Y. Macromol Chem Phys 2006, 207, 820-826.

7 Akat, H.; Tasdelen, M. A.; Du Prez, F.; Yagci, Y. Eur Polym J 2008, 44, 1949-1954.

8 Oral, A.; Tasdelen, M. A.; Demirel, A. L.; Yagci, Y. Polymer 2009, 50, 3905-3910.

9 Bottcher, H.; Hallensleben, M. L.; Nuss, S.; Wurm, H.; Bauer, J.; Behrens, P. J Mater Chem 2002, 12, 1351-1354.

10 Salem, N.; Shipp, D. A. Polymer 2004, 46, 8573-8581.

11 Zhang, B. Q.; Pan, C. Y.; Hong, C. Y.; Luan, B.; Shi, P. J Macromol Rapid Commun 2006, 27, 97-102.

12 Konn, C.; Morel, F.; Beyou, E.; Chaumont, P.; BourgeatLami, E. Macromolecules 2007, 40, 7464-7472.

13 Ding, P.; Zhang, M.; Gai, J.; Qu, B. J. J Mater Chem 2007, 17, 1117-1122.

14 Yenice, Z.; Tasdelen, M. A.; Oral, A.; Guler, C.; Yagci, Y. J Polym Sci Part A: Polym Chem 2009, 47, 2190-2197.

15 Behling, R. E.; Williams, B. A.; Staade, B. L.; Wolf, L. M.; Cochran, E. W. Macromolecules 2009, 42, 1867-1872.

16 Messersmith, P. B.; Giannelis, E. P. Chem Mater 1993, 5, 1064-1066.

17 Messersmith, P. B.; Giannelis, E. P. J Polym Sci Part A: Polym Chem 1995, 33, 1047-1057.

18 Kubies, D.; Pantoustier, N.; Dubois, P.; Rulmont, A.; Jerome, R. Macromolecules 2002, 35, 3318-3320.

19 Lepoittevin, B.; Pantoustier, N.; Devalckenaere, M.; Alexandre, M.; Kubies, D.; Calberg, C.; Jerome, R.; Dubois, P. Macromolecules 2002, 35, 8385-8390.

20 Viville, P.; Lazzaroni, R.; Pollet, E.; Alexandre, M.; Dubois, P. J Am Chem Soc 2004, 126, 9007-9012.

$21 \mathrm{Di}$, J. B.; Sogah, D. Y. Macromolecules 2006, 39, 5052-5057.

22 Tasdelen, M. A. Eur Polym J 2011, 47, 937-941.

23 Yoonessi, M.; Toghiani, H.; Kingery, W. L.; Pittman, C. U. Macromolecules 2004, 37, 2511-2518.

24 Yoonessi, M.; Toghiani, H.; Daulton, T. L.; Lin, J. S.; Pittman, C. U. Macromolecules 2005, 38, 818-831.

25 Yoonessi, M.; Toghiani, H.; Pittman, C. U. J Appl Polym Sci 2006, 102, 2743-2751.

26 Tasdelen, M. A.; Van Camp, W.; Goethals, E.; Dubois, P.; Du Prez, F.; Yagci, Y. Macromolecules 2008, 41, 6035-6040.

27 Oral, A.; Tasdelen, M. A.; Demirel, A. L.; Yagci, Y. J Polym Sci Part A: Polym Chem 2009, 47, 5328-5335.

28 Malucelli, G.; Bongiovanni, R.; Sangermano, M.; Ronchetti, S.; Priola, A. Polymer 2007, 48, 7000-7007.

29 Ceccia, S.; Turcato, E. A.; Maffettone, P. L.; Bongiovanni, R. Prog Org Coat 2008, 63, 110-115. 
30 Zhou, Q. Y.; Fan, X. W.; Xia, C. J.; Mays, J.; Advincula, R. ChemMater 2001, 13, 2465-2467.

31 Fan, X. W.; Zhou, Q. Y.; Xia, C. J.; Cristofoli, W.; Mays, J.; Advincula, R. Langmuir 2002, 18, 4511-4518.

32 Tasdelen, M. A.; Kreutzer, J.; Yagci, Y. Macromol Chem Phys 2010, 211, 279-285.

33 Yagci, Y.; Jockusch, S.; Turro, N. J. Macromolecules 2010, 43, 6245-6260.

34 Yagci, Y. Macromol Symp 2000, 161, 19-35.

35 Tasdelen, M. A.; Moszner, N.; Yagci, Y. Polym Bull 2009, 63, 173-183.

36 Tasdelen, M. A.; Kumbaraci, V.; Talinli, N.; Yagci, Y. Polymer 2006, 47, 7611-7614.

37 Tasdelen, M. A.; Demirel, A. L.; Yagci, Y. Eur Polym J 2007, 43, 4423-4430.
38 Cokbaglan, L.; Arsu, N.; Yagci, Y.; Jockusch, S.; Turro, N. J. Macromolecules 2003, 36, 2649-2653.

39 Aydin, M.; Arsu, N.; Yagci, Y.; Jockusch, S.; Turro, N. J. Macromolecules 2005, 38, 4133-4138.

40 Aydin, M.; Arsu, N.; Yagci, Y. Macromol Rapid Commun 2003, 24, 718-723.

41 Temel, G.; Arsu, N.; Yagci, Y. Polym Bull 2006, 57, 51-56.

42 Yilmaz, G.; Aydogan, B.; Temel, G.; Arsu, N.; Moszner, N.; Yagci, Y. Macromolecules 2010, 43, 4520-4526.

43 Yilmaz, G.; Tuzun, A.; Yagci, Y. J Polym Sci Part A: Polym Chem 2010, 48, 5120-5125.

44 Dyer, D. J.; Feng, J. X.; Schmidt, R.; Wong, V. N.; Zhao, T. F.; Yagci, Y. Macromolecules 2004, 37, 7072-7074.

45 Hirata, T.; Kashiwagi, T.; Brown, J. E. Macromolecules 1985, $18,1410-1418$. 